same as the external surface. Gall bladder distended with bile.

Spleen.- This was found to be large, weight $1 \frac{1}{2} \mathrm{lb}$., soft and dark in appearance. On section my first remark was, " It cuts like a clot of blood." It was found to be very friable and the cut surface was diffluent. Pancreas appeared normal. Lungs appeared normal.

Heart and pericardium. - Pericardium contained more than the normal amount of fluid. No evidence of pericarditis was present. Heart was soft and flabby, distended with blood, in asystole. A blood slide was taken from the heart blood; also a smear from the spleen. No edema. No evidence of renal disease. Nothing else was noted from the normal.

I was satisfied that the case was not one of acute poisoning or a suicide, but felt sure that the cause must be toxic. The man had not eaten anything to give him ptomaine poisoning so far as I could ascertain, so this cause could be excluded.

My first concern was, that I must be satisfied that I was not dealing with a quarantinable disease. Choleraic symptoms had predominated, but finding a fluid in the intestines which was not rice water in character, but apparently serous and bile stained, settled the question negatively for cholera. I was puzzled for a short time. Then I thought that the spleen was certainly malarial and was indicative of the probable illness, and this conformed with the first impression that the man was a malarial cachetic. I then made the provisional diagnosis of acute malarial toxemia of the algid form, choleraic type.

I left the examination of my slides for the next morning. These were stained with Wright's polychrome methylene blue. The blood slide was a poor one, but I found a clear area under low power where the blood cells seemed to be flat and separate. I then examined this under high power and was struck with the presence of so much black pigment free and in white cells. The red blood cells showed a small ring form of the malarial parasite with its thin blue ring and red chromatin spots. Nearly every cell was so infected with one or two to three such young parasites. This was conclusive that it was malaria. The slide made from the spleen was then examined and found to be full of pigmented bodies. I reasoned then that the appearance of the mucous membrane must have been due to pigment which blocked the capillaries; that the appearance of the mesentery and omentum was due to the same condition.

Sections made of the liver and spleen tissues, stained with hemalum and eosin, showed them to be full of hemozoin in granules and large and small masses.

I regret that a blood count was not made, as there was unquestionably a marked, at least relative, leucocytosis. A differential leucocyte count from two slides gave the following results:

$$
\begin{aligned}
& \text { Small mononuclear leucocytes, } \quad 1,743 \\
& \begin{array}{lr}
\text { L" pigmented, } & 25 \\
\text { Large mononuclear leucocytes, } & 288
\end{array} \\
& \begin{array}{ll}
\text { P’’ pigmented, } & 173 \\
\text { Polymorphonuclear leucocytes, } & 269
\end{array} \\
& \text { Eosinophiles, " pigmented, } 68 \\
& \text { Total, } \\
& \overline{2,570}
\end{aligned}
$$

I can at least safely report a marked leucocytosis, as may be judged from the above count.

I suppose that treatment would have availed had the case been recognized earlier, but certainly not at the time the case was seen by me. Had the man presented even a slight elevation of temperature I would surely have made a blood examination at the time of my first inspection, and would have given him quinine even if the examination had proven negative, as I would have been guided by the malarial aspect presented.

I frankly admit that I did not diagnose or even suspect the true character of the disease until after the autopsy was made by me.

The history just given was submitted to the surgeon-general's office and a copy also sent to Surgeon M. J. Rosenau, Director of the Hygienic Laboratory. Dr. Rosenau in his letter to me says, "He surely had an accesso pernicioso." “ Don't you suppose, however, that he might have been sick on the trip and that when you saw him he was suffering with the stupor due to clogging of the capillaries of the brain with malarial pigment and parasites?"

I believe this was probable.

To recapitulate. We had a case presenting:

Illness of about six hours; symptoms of cholera; no fever; syncope and death.

Post mortem: Enlarged liver and spleen; discolored mucous membrane of stomach; discolored mesentery and omentum; sections of liver and spleen showed hemozoin in large and small masses; young small ring form of malarial parasites in red blood cells and some free in the blood; hemozoin in white blood cells chiefly mononuclears; lymphocytosis; free hemozoin in blood.

\section{TWO CASES OF CARCINOMA OF THE BLADDER TREATED WITH INJECTIONS OF TRYPSIN.}

$$
\text { BY R. H. GILPATRICK, M.D., Boston. }
$$

THe following cases occurred at the Boston City Hospital, on the service of Dr. G. H. Monks, to whom I am indebted for the privilege of reporting them.

CaSE I. B. C. Female forty-four years, married, was admitted to the second surgical service, Boston City Hospital, May 29, 1907. Family history negative. Mother of six healthy children. At admission her only complaint was of a lump in the left groin which she said had appeared there four days before. She had vomited each of the four days and the bowels had moved each day.

Physical examination showed a well-developed and nourished woman. Except for pallor and a dirty coated tongue, examination was negative. Left femoral region presented a tumor the size of a hen's egg, slightly reddened, painful, tender, not fluctuating and dull to percussion. A diagnosis of strangulated omental hernia was made and operation done.

Incision revealed much edema of tissues and an abscess cavity in which was about an ounce of pus about a mass of inflamed glands. These were removed and the cavity packed with iodoform gauze and dressed.

Pathological examination showed the glands to be epidermoid carcinoma. With this knowledge in hand 
an attempt was made to obtain a history of previous symptoms but without success. Vaginal examination showed a carcinomatous growth of utterly inoperable proportions involving the bladder and anterior vaginal wall. The operation wound did well, but within a few days patient began to complain of frequent and painful micturition. Hematuria was first noted two days after operation. Micturition rapidly became more frequent and painful and hematuria continued. Treatment with injection of trypsin was begun three days after operation. At first 10 minims were injected into the body of the tumor every other day. The dose was rapidly increased to 25 minims, and 5 minims of a $2 \%$ solution of cocaine given with each dose controlled the pain of the injection.

Patient's condition grew rapidly worse. Pain became constant and required morphia frequently. She became incontinent and rapidly increasing glands were noted in both groins. General tonic and supportive treatments were kept up. The course of her disease was apparently not at all influenced by the treatment. Seven weeks after operation she was discharged to her friends that she might die at home. She was lost sight of but her condition was hopeless.

CASE II. M. B. Female, seventy-eight years. Married. Admitted March 31, 1907. Family history and past history good. She had noticed her urine to be bloody for two weeks. Urination had been painful for ten days and of increasing frequency. Examination showed a well-developed and fairly nourished woman, somewhat senile, but arteries in good condition. There was a systolic murmur at the cardiac apex. Vaginal examination showed considerable thickening and induration of the anterior wall with several hard nodular tender tumors apparently involving the bladder. Urine was bloody. Under rest in bed and general treatment hematuria ceased. Cystoscopy eight days after entrance showed a nodular bladder wall much inflamed. Several nodules projected into the bladder and were evidently continuous with nodules seen in vaginal wall. A bit of tissue was removed from the vaginal wall and proved to be carcinoma. After cystoscopy micturition was frequent and very painful. she became incontinent, vomited occasionally and was unable to sit up in bed at the end of two weeks on account of pain and weakness. Cachexia rapidly developed and a small decubitus appeared over the sacrum. Pain was such as to require morphia.

On April 19, she was still failing and condition became critical. Injections of trypsin were begun as in Case $I$ and continued as before. Cocaine was used as in Case 1.

Her condition remained critical for about ten days, when it began to improve. On June 1 there was a well marked improvement. Tongue had cleaned up and a fair amount of nourishment was being taken. Pain was much less and hematuria had ceased. The injections were kept up as before. On June 8 she sat up a short time and continued to improve. On July 13 she walked out of the hospital. At this time the anterior vaginal wall was still considerably thickened but the nodules had decreased markedly in size. Urine was passed about once in an hour and three times at night. She had gained much in weight.

Seen on July 30 . General condition much as at th discharge. She is up and about most of the day. She sleeps well and complains of no pain. There has been no hematuria. She was seen to go up an ordinary flight of stairs slowly.

From the time of discharge until Sept. 1 she received no treatment. On that date her old symptoms had begun to return and treatment was begun as before. The conditions were less favorable, as she was at this time keeping house for herself and son. The bladder symptoms were controlled as before, but soon signs of gastric disturbance were noted, and by Oct. 1 a well defined tumor was felt in the pyloric region. Patient's condition rapidly failed. Marked evidence of pyloric obstruction appeared. She died three weeks later and an autopsy was refused.

No general conclusions can be drawn from so small a number of cases, but the fact that in Case II the treatment seemed to relieve the local condition both early and late offers encouragement for further trial.

\section{Mqedical Brogregs.}

REPORT ON I'EDIATRICS.

BY THOMAS MORGAN ROTCH, M.D., AND JOHN LOVETT MORSE, M.D. NEUTROPHILIC BLOOD IN INFANCY.

(1) The neutrophilic blood picture in naturally and artificially-fed infants.

Esser ${ }^{1}$ found that the neutrophilic blood picture was at first turned to the left but was much like the adult after a few weeks, rather more corpuscles, however, being at the extreme right. Otherwise the picture corresponded to that in adults. The neutrophilic blood picture in infancy reacts to disease as it does in the adult. He found great differences in the blood picture in breast and artificially fed babies. In the artificially fed the blood picture was like that in the adult; that is, there were less cells at the right. In diseased conditions, especially of the gastroenteric tract, great variations occurred in the blood picture. It shifted to the left on cow's milk and other artificial foods.

(2) The neutrophilic blood picture in healthy and sick infants.

Zelenski ${ }^{2}$ found from his own observations two marked peculiarities in the blood pictures of infancy. The reaction of the neutrophilic corpuscles brought on by disease was as a rule stronger than in adults and at times reached a grade never found outside of infancy. This reaction resulted even in its most marked type from apparently insignificant and unimportant diseased conditions; in many cases, indeed, without any evidence whatever of disease. $\mathrm{He}$ found, in contra-distinction to Esser, that the neutrophilic picture was the same in both the normally and the artificially fed.

\section{CLASSIFICATION OF THE INFANTILE ANEMIAS.}

Simon $^{3}$ does not believe that the study of the blood is far enough advanced at present to justify any accurate classification. He merely divides the blood conditions into various types, as follows: simple anemia, anemia of the chlorotic type (oligosideremia), pernicious anemia, anemia with splenic tumor, leukemia.

Simple anemia. - The babies show evidences of malnutrition and are irritable. Digestive disturbances are frequent. The liver, spleen and lymph nodes are not enlarged. The blood shows 